\title{
On Predicting the Ultimate Capacity of a Large-Span Soil-Steel Composite Bridge
}

\author{
Amer Wadi $^{1,2}$ (1) $\cdot$ Lars Pettersson $^{3} \cdot$ Raid Karoumi $^{1}$
}

Received: 27 July 2020 / Accepted: 30 September 2020 / Published online: 17 October 2020

(c) The Author(s) 2020

\begin{abstract}
The limit state design of large-span soil-steel composite bridges (SSCB) entails that understanding their structural behaviour in the ultimate state is as much needed as their performance under service conditions. Apart from box culverts, the largest loading-to-failure test was done on a 6.3-m span culvert. More tests on larger spans are believed essentially valuable for the development of the design methods. This paper presents the numerical simulation efforts of an 18.1-m span SSCB pertaining to its ongoing preparations for a full-scale field test. The effect of the different loading positions on the ultimate capacity is investigated. Comparisons are made between three-dimensional (3D) and two-dimensional (2D) models. The results enabled to realise the important role of the soil load effects on the ultimate capacity. It is found that the failure load is reduced when the structure is loaded in an asymmetrical manner. A local effect is more pronounced for the live load when the tandem load is placed closer to the crown. The study also illustrates the complex correlation between 3D and 2D models, especially if one attempts to simultaneously associate sectional forces and displacements.
\end{abstract}

Keywords Flexible culvert · Soil-steel composite bridge · Corrugated steel · Finite element model · Ultimate limit state · Failure test $\cdot$ Large-span

\section{Introduction}

The design methods for soil-steel composite bridges (SSCB) are generally based on both theoretical and experimental tests. The ring compression theory developed by White and Layer [1] entails that flexible culverts are simply designed for a prevailing normal force in the wall conduit. Later, this was seen inadequate as SSCBs became bigger and the design demanded for heavier concentrated loads under shallow depths of soil cover. Thereafter, the soil-culvert interaction (SCI) $[2,3]$ has considered the flexural capacity of SSCB, where design calculations involved bending moments as well as normal forces. The SCI work was mainly based on 2D finite element method models (FEM) where the load

Amer Wadi

wadi@kth.se

1 KTH Royal Institute of Technology, 10044 Stockholm, Sweden

2 ViaCon International AB, 53102 Lidköping, Sweden

3 Skanska Sweden AB-Major Projects, 11274 Stockholm, Sweden effects from the soil and the live loads are analysed. In addition, the research work presented by Klöppel and Glock [4] has also investigated the load carrying behaviour of flexible embedded pipes. These efforts are considered bases for different design methods such as the Swedish design method (SDM) $[5,6]$ and the Canadian Highway Bridge Design Code (CHBDC) [7]. Both SDM and CHBDC have used the research output from different field/lab tests in the development process [5, 8]. Furthermore, AASHTO [9] considers the concept of the ring compression theory for the relatively small span structures but have also design specifications for large spans. The recommended specifications for large-span culverts in the AASHTO were based on the research output from a field testing of a 9.5-m span metal arch together with FEM [10, 11]. It is no secret that the majority of these design methods are continuously being developed to meet new market challenges (larger spans/shallow covers) and to keep up to date with the new technologies in terms of production techniques and new corrugations.

Limit state design requires design verifications in the different states which may include serviceability, fatigue, and ultimate state design. Thus, the calculation of load effects should realistically reflect any behaviour differences for the 
various states of design. For a SSCB, there is a high level of nonlinearity mainly due to the soil $[2,12]$ and the interaction [3, 13-15] between the two materials. The nonlinearity of the soil certainly relates to the structural performance of SSCB for the different limit states. Despite being expensive, different field/lab tests were done studying the backfilling phase [16, 17], the dynamic response [18-22], the fatigue [23], the service performance [24-33], and the ultimate limit state $[4,34-38]$. These tests were seen essential as they provide vital information about the performance of these composite structures for the different conditions of loading. Furthermore, the various efforts of computer simulations [2, $3,11,13-15,17,19,39-53$ ] have allowed for more extensive analyses and performance predictions. The few ultimate field tests in the literature dealt with closed profiles $[4,35$, $36,38]$ up to $6.3-\mathrm{m}$ span and box culverts up to $14-\mathrm{m}$ span $[34,37,46,54]$. Despite the several field tests on SSCB in different conditions, there is still a need to do more tests on a regular (not a box culvert) large-span structures (more than $15-\mathrm{m}$ span). This is particularly needed to compare the relevancy of the different design approaches for large spans. The understanding of behaviour of large-span SSCB in the ultimate state is as much needed as their performance under service conditions. The different configuration of load models in the different design standards entails further investigations of critical load positions particularly in the case of large-span structures.

FEM can be a valuable tool in the preparation process of any full-scale field test. It provides beforehand information regarding the structural behaviour under different loading schemes and helps a great deal in establishing an efficient instrumentation plan for the structure. An ambitious plan has been initiated to perform a full-scale field test on a largespan structure. The initiative involves performing field measurements including service and ultimate load testing for a two-radius arch of an 18.1-m span. The paper presents part of the ongoing test preparations where FEM is used for the performance prediction of the structure. Extensive 3D FEM is presented for the prediction of the ultimate capacity for different loading schemes using a standard load model. The study also highlights differences between 2D and 3D models for the case. Although the paper is based on numerical simulations, the modelling methodology itself is similar to an earlier investigation of a calibrated case study [13]. Furthermore, the study is believed to provide important insights regarding performance analyses and predictions of largespan corrugated steel bridges.

\section{Aim and Scope}

This investigation aims to present the numerical simulation efforts of a two-radius high profile SSCB pertaining to the ongoing preparations of a full-scale field test for the case. The study seeks to analyse and discuss the structural ultimate limit state performance taking into consideration different loading positions for a standard load model. While the study does not really focus on the geotechnical limit state (e.g. soil failure due to excessive displacement under the load, global soil instability), geotechnical consideration is surely an important aspect in the design process. In that context, soil displacements under the live load are briefly highlighted in "Load-displacement curves". The anticipated structural response from the backfilling is also included and linked to limited field measurements of a comparable case. In addition, the study examines the structural response by comparing differences between 3D and 2D simulations. Discussions regarding critical load position, mechanism of failure, and the distribution of load effects are presented. The simulations are based on a certain depth of soil cover being $700 \mathrm{~mm}$, and a standard load configuration that is normally used for the design of bridges in Europe. The study does not involve model calibration because it is conducted for a performance prediction of the studied case ahead of its field testing. However, the modelling methodology itself is similar to an earlier investigation of a calibrated case study [13]. It is seen purposeful to present these results ahead of the test for their conceptual relevance and novelty. While the article is believed to provide valuable insights regarding the anticipated performance of a large-span SSCB, the results will be also used in deciding particulars of the upcoming field test. These include the instrumentation plan, loading scheme, the anticipated magnitude and distribution of the sectional forces (i.e. stress resultants) in the structure.

\section{Case Study and Load Model}

The selection of the case study was initially based on having a similar overall stiffness/geometry with a recently built structure in Poland [55]. The 25.8-m span structure was a two-radius profile arch made of steel corrugations $500 \mathrm{~mm} \times 237 \mathrm{~mm}$. Since the plan was set to test a SSCB with steel corrugations $381 \mathrm{~mm} \times 140 \mathrm{~mm}$, the corresponding span with a similar overall stiffness (soil modulus $\times \operatorname{span}^{3} /$ bending stiffness, $E_{\text {soil }} \times D^{3} / E_{\mathrm{s}} \times I_{\mathrm{s}}$ ) would be of about $16 \mathrm{~m}$. Eventually, the selection was made on a standard profile shape [56] of a two-radius arch having an 18.1-m span and a total height of $5.6 \mathrm{~m}$ (Fig. 1). The thickness of the steel corrugation was set to $7 \mathrm{~mm}$. The steel thickness was selected based on maximum standard steel thicknesses for this corrugation size. The ratio between the top to side plates radii is equal to 4 .

Road bridges are generally designed for standard load models that are defined in accordance with the respective country's specifications. These load models can be different in their configuration and magnitude [7, 9, 57]. Previous 


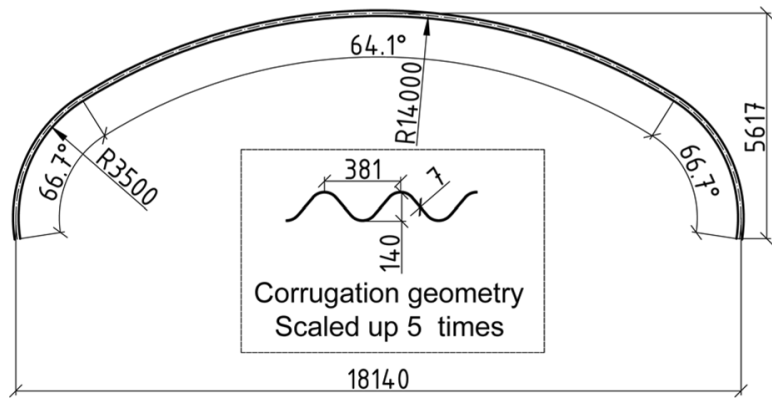

Fig. 1 Geometry of the case study and corrugation (mm)

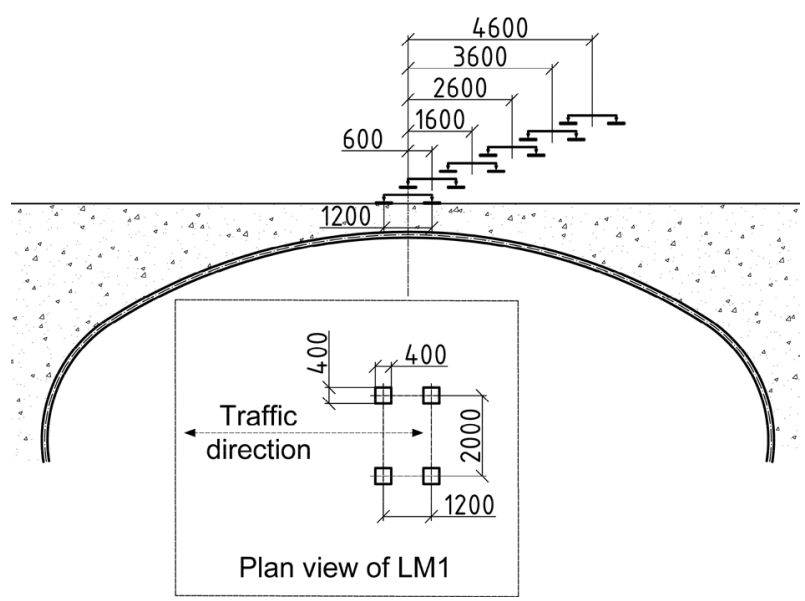

Fig. 2 Definition of load and different load positions (mm)

loading-to-failure tests on SSCB have used load details that were meant to represent applicable load models at the place of the tests $[34,35,37,38,46]$. One may compare the different definitions of the road load models in the different codes. For instance, the standard tandem traffic load in Europe [57] (load model 1, LM1) comprises of two 300-kN axles separated by a 1.2-m distance (Fig. 2). The magnitude of the axle load can be different depending on county's specific national annexes. On the other hand, the general truck definition for CHBDC [7] (truck CL-625) consists of five axles with a total load of $625 \mathrm{kN}$. The $2 \mathrm{nd}$ and the $3 \mathrm{rd}$ axles have $1.2-\mathrm{m}$ distance, and each has $125-\mathrm{kN}$ axle load. The 4th axle is the heaviest with $175 \mathrm{kN}$ located at $6.6 \mathrm{~m}$ from the 3rd axle. Although the total load of these two load models is almost the same, their load configuration would normally result in a different design outcome for SSCB. This is a consequence to the fact that design methods normally use the increase of the vertical soil pressure at the crown from the live loads for the calculation of live loads effects, and the magnitude of this pressure is largely dependent on the live load configuration at the soil surface.One may also compare AASHTO HL-93 design truck [9], which has three axles of $35 \mathrm{kN}, 145 \mathrm{kN}$, and $145 \mathrm{kN}$ for the $1 \mathrm{st}, 2 \mathrm{nd}$ and $3 \mathrm{rd}$ axle loads, respectively.
The distance between the rear axles varies between 4.3 and $9 \mathrm{~m}$ and the $1 \mathrm{st}$ axle is $4.3 \mathrm{~m}$ away from the $2 \mathrm{nd}$. Since the test primarily aims to evaluate large-span SSCB performance in Europe, the simulations will principally use the standard tandem load model 1 (LM1) as defined by EN 1991-2 [57] for road bridges in Europe (Fig. 2). To study the effect of different load positions, six different locations were simulated, and they are designated by the distance of the tandem centre to the crown line of the structure (Fig. 2). The 700-mm soil cover was chosen to practically allow to bring the structure to failure at the test site.

\section{Numerical Simulation}

Since the study deals with SSCB performance under live loads, it becomes natural to utilise 3D FEM where the load distribution and the orthotropic behaviour of the corrugated steel plate can be reasonably captured. Therefore, the study not only will focus on results from 3D FEM but also compares main differences with 2D simplified models. The investigation was performed using the FEM program Abaqus [58].

\section{D Model}

The 3D model was constructed by assuming that the test will be performed on a 5-m-wide arch segment which is close to previous full-scale tests with a comparable load width and corrugation [34]. One should keep in mind that in a real design project case, the structure can have a wider width, including details of the end treatment, which may affect the 3D structural response. In the present work, and to reduce the size of the model, half of the structure was modelled due to the symmetry in one plane (Fig. 3). Six load positions were investigated to study changes in the structural behaviour and to seek for critical load position for the ultimate load test (Fig. 2). The use of full models (without symmetry) for two load positions was also discussed in "Effect of using symmetry and interface modelling choice". The selected tandem load of LM1 was applied using displacement control of two 50-mm-thick steel plates on the soil surface. Each plate had the dimension of the wheel footprint being $0.4 \mathrm{~m} \times 0.4 \mathrm{~m}$, which are the standard dimensions of LM1. The extent of the soil volume around the steel arch was assumed based on minimum requirements in SDM [6]. The orthotropic behaviour of the steel arch was modelled by including the corrugation geometry itself in the constructed model. This is believed important where a previous study [46] showed that equivalent orthotropic analysis might not be accurate especially for the case of the ultimate load. The soil was modelled using a Mohr-Coulomb material model with an elastic soil modulus $E_{\text {soil }}=60 \mathrm{MPa}$ and a peak 
Fig. 3 View of 3D and 2D models

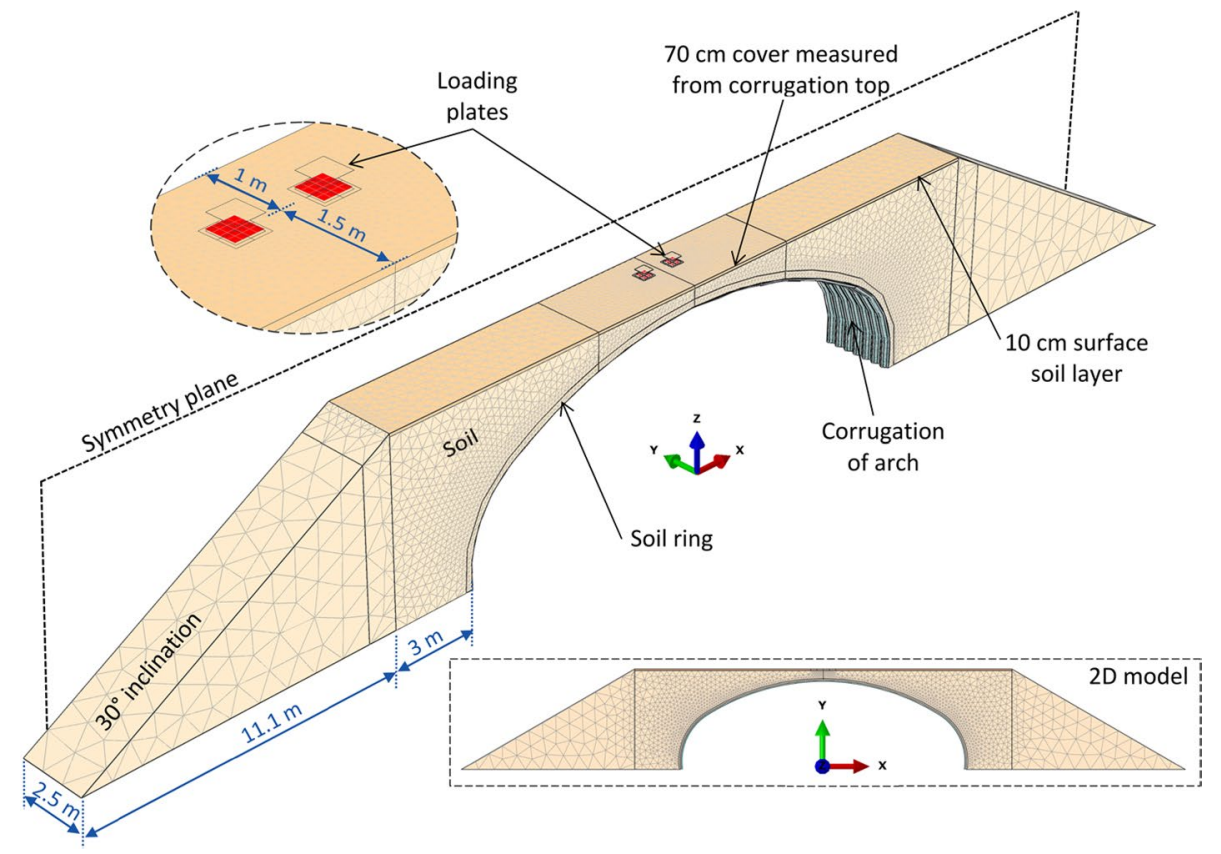

friction angle $\varphi=45^{\circ}$. The cohesion for the soil was set to $5 \mathrm{kPa}$ except for a $0.1-\mathrm{m}$-depth surface layer which had a higher cohesion value of $10 \mathrm{kPa}$ (Fig. 3). The reason for this was to avoid a premature calculation termination at low load due to a soil failure at the surface. The dilation angle $\psi$ of the soil was assumed to follow $\psi=\varphi-30^{\circ}$ [59]. To allow for relative movements at the interface between the soil and the steel arch, the interface was basically modelled assuming a frictional contact with a friction coefficient $\mu=0.4$. Given the nature of the study (a performance prediction ahead of field testing), the assumed friction coefficient was based on a general suggested value for the interface between steel and gravel-sand mixtures [60]. A highlight on the effect of a tied interface is also discussed. Poisson's ratio for both the soil and steel was set to 0.3 and the soil density was set to $2000 \mathrm{~kg} / \mathrm{m}^{3}$. Geometric nonlinearities were considered in the simulations by taken into consideration second-order effects from large deformations.

The soil was modelled using quadratic tetrahedral solid elements of type C3D10 and the steel arch corrugation was modelled using linear quadrilateral shell elements of type S4R with finite strain shell element formulation. The global mesh size for the steel arch was $10-\mathrm{cm}$ with $2-\mathrm{cm}$ mesh refinement along the corrugated curves. The global mesh size for the soil was $1 \mathrm{~m}$ with $40-\mathrm{cm}$ refinement for the soil surrounding the arch. A local mesh refinement was used along a soil ring (0.15-m mesh size) around the arch and a mesh refinement of $0.1 \mathrm{~m}$ for soil volume near the loading pads. The different mesh sizes were chosen based on the convergence of the results and the calculation time. Symmetry boundary condition was applied of the vertical soil surface in $Y$ direction and all the other vertical soil surfaces were restrained in the horizontal normal direction. This is under the assumption that the horizontal movements-in the normal direction —of the soil due to the live load is minimal at that distance from the applied load. This was checked by running a full elastic model $\left(E_{\text {soil }}=30 \mathrm{MPa}\right)$ with no horizontal restraints on the backfill soil side (the side where there is no symmetry plane). In addition, for instance, a live load distribution $(2 \mathrm{~V}: 1 \mathrm{H})$ through the soil cover is not violated by the presence of the restrained vertical soil surface. Symmetry boundary conditions were applied to the corrugated steel shell on the side of the symmetry plane. The remaining side of the shell was left free from any restraints (Fig. 3). The movement of the bottom soil surface was restrained in all three directions. The yield strength of the corrugated steel was set to $355 \mathrm{MPa}$ defined as von Mises yield criteria. This is a standard steel grade for this corrugation size [56]. In reality, the forces in the steel arch are transferred to the bedding soil through some kind of foundations (normally concrete footing). However, footings were not included, and both ends of the steel arch were pinned to a rigid base. In a way, displacement constraints were applied to the centroid of the corrugated section to allow for a free in-plane rotation.

\section{D Model}

The 2D model had the same configuration and input parameters regarding the soil (Fig. 3). The corrugated steel arch was modelled as $2 \mathrm{D}$ beams with a rectangular section using an equivalent thickness $t_{\mathrm{eq}}$ and an equivalent Young's modulus $E_{\text {eq }}$. The section properties in the circumferential direction of the corrugated plates were used. The longitudinal direction of the corrugation is not applicable in a 2D model.The 
equivalent 2D parameters $\left(t_{\mathrm{eq}}\right.$ and $\left.E_{\mathrm{eq}}\right)$ were calculated using Eqs. (1) and (2) by equating the circumferential bending and axial stiffnesses of the corrugated plate to the equivalent bending and axial stiffnesses of the $2 \mathrm{D}$ rectangular beam. The input parameters for the $381 \mathrm{~mm} \times 140 \mathrm{~mm}$ corrugation were used being thickness $t_{\mathrm{s}}=7 \mathrm{~mm}$, cross-sectional area $A_{\mathrm{s}}=9.05 \mathrm{~mm}^{2} / \mathrm{mm}$, and moment of inertia $I_{\mathrm{s}}=20,997 \mathrm{~mm}^{4} /$ $\mathrm{mm}$. The Young's modulus of steel was assumed $E_{\mathrm{s}}=210$ $\mathrm{GPa}$. The width of the model was $1 \mathrm{~m}$.

$t_{\mathrm{eq}}=\sqrt{\frac{12 I_{\mathrm{s}}}{A_{\mathrm{s}}}}=167 \mathrm{~mm}$,

$E_{\mathrm{eq}}=\frac{12 E_{\mathrm{s}} I_{\mathrm{s}}}{t_{\mathrm{eq}}^{3}}=11.39 \mathrm{GPa}$.

Knowing that the 2D model may not be specifically sufficient in capturing failure loads, it would be interesting to look at the different failures for the different load positions. Hence, the equivalent yield stress $f_{\text {yeq }}$ was calculated using Eq. (3) by assuming that the elastic moment capacity of the corrugated and the 2D sections is the same. This was calculated using the elastic section modulus of the corrugation $W_{\mathrm{s}}=285.7 \mathrm{~mm}^{3} / \mathrm{mm}$, the elastic section modulus of the $2 \mathrm{D}$ equivalent beam $W_{\mathrm{eq}}=4640.4 \mathrm{~mm}^{3} / \mathrm{mm}$ and the assumed yield strength of the steel being $f_{\mathrm{y}}=355 \mathrm{MPa}$.

$f_{\mathrm{y}, \mathrm{eq}}=\frac{f_{\mathrm{y}} W_{\mathrm{s}}}{W_{\mathrm{eq}}}$.

The soil was modelled using quadratic triangular elements of type CPE6M and the steel arch beam was modelled using linear beam elements of type B23. The mesh size for the steel arch was $10 \mathrm{~cm}$ and the global mesh size for the soil was $1 \mathrm{~m}$ with $40-\mathrm{cm}$ refinement for the soil surrounding the arch. A local refinement of $0.15-\mathrm{m}$ mesh size was used along a soil ring around the arch and a similar refinement was used for the loaded edges of the soil surface. The live load was applied using displacement control of two strips of $40 \mathrm{~cm}$ each representing the one-side dimension of the load footprint (Fig. 2). The steel arch was pinned at both ends.

\section{Backfilling of Soil}

The induced stress state in the arch by the backfilling process plays an important role in defining the ultimate capacity of the structure. Therefore, these stresses were predicted by applying a prescribed displacement on the soil ring around the arch (Fig. 4). The magnitude and the distribution of this displacement were approximately derived from a simplified equivalent 2D model using a multilayer backfilling model similar to the method used in earlier 2D studies $[49,50]$.

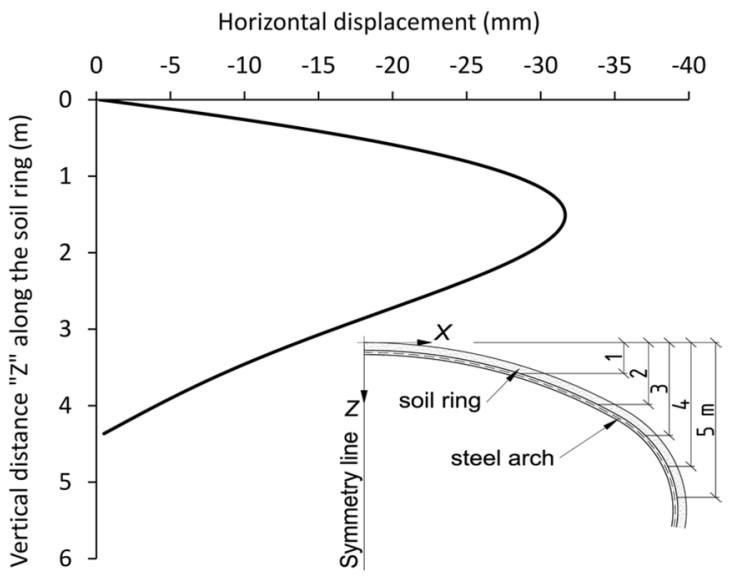

Fig. 4 Distribution of the prescribed horizontal displacement to simulate the stress state from the backfilling

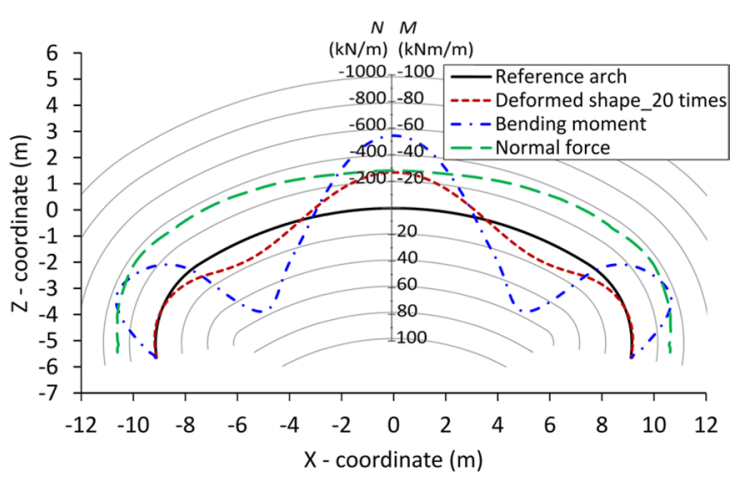

Fig. 5 Soil load effects based on the 3D model

This displacement was applied at once after the completed soil and then deactivated in the next analysis step prior to applying the tandem load increments. This technique was used in an earlier study [13] and believed to be effective in achieving the desired stress state in the arch prior to the application of the live load. The predicted forces from the backfilling were judged comparable to limited measurements of a close-size structure [61] as it will be seen in "Soil load effects".

\section{Results and Discussion}

\section{Soil Load Effects}

The use of the prescribed displacement explained in "Backfilling of soil" resulted in a similar structural response for both the 2D and the 3D models. For instance, and based on the results of the 3D model, the crown point had an upward displacement of $68 \mathrm{~mm}$ and a maximum negative bending moment of $-56 \mathrm{kNm} / \mathrm{m}$ (Fig. 5). The normal forces had 
small variations along the arch and a maximum positive bending moment was observed at about 6-m $x$-distance from the crown line. These results are believed realistically close if one compares values from a comparable size structure (17.7-m span) reported by Korusiewicz and Kunecki [61]. Obviously, the used method in the model does not predict the maximum response (bending moments and displacement) of the arch during the backfilling, which is normally occurring when the backfill level is at the crown. However, if one uses the method described by Wadi et al. [49, 50], the method will predict a maximum vertical displacement of the crown of around $85 \mathrm{~mm}(0.5 \%$ of the span) and a maximum negative bending moment of $-67 \mathrm{kNm} / \mathrm{m}$ both occurring when the backfill level reaches the crown. This is again considered realistic compared to the 17.7-m span tested structure [61], where it had a maximum negative bending moment and a deflection of $-54 \mathrm{kNm} / \mathrm{m}$ and $80 \mathrm{~mm}$, respectively.

\section{Load-Displacement Curves}

Load-deflection curves can provide valuable information regarding the overall stiffness of the structure and the failure load for the different load positions. Figures 6 and 7 show the different load-displacement curves for both 3D and 2D models. The applied tandem load was back-calculated from the reaction forces of the applied displacement (in this case, at a controlled node). It is worth mentioning that total load in Fig. 7 represents the overall applied load for the two load strips. Both Figs. 6 and 7 show similar trends in terms of critical load positions and the overall structural stiffness. Obviously, the structure tends to be stiffer when the load is applied away from the crown and at the same time these load cases represent critical load positions for the failure load. The resulted load-displacement curves from the 2D models need to be somehow linked to the applied tandem loads from the 3D models. One may try to find the corresponding total load in the 2D model that leads to the same overall

Tandem load (kN)

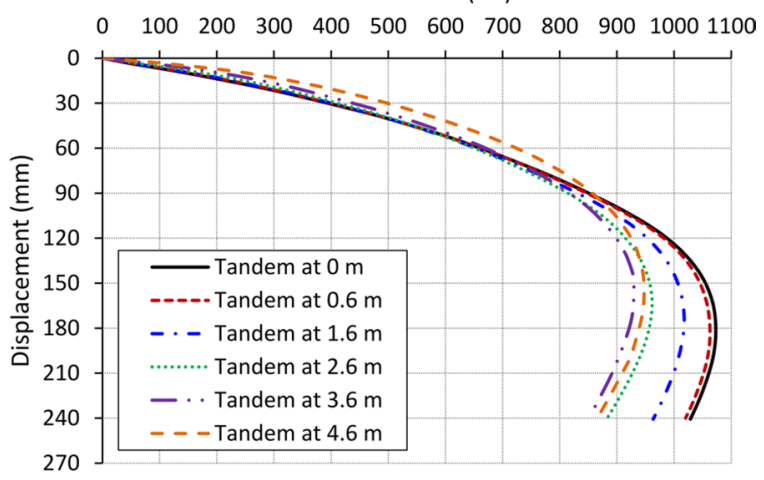

Fig. 6 Load-displacement curves for the different load positions as extracted form $3 \mathrm{D}$ models

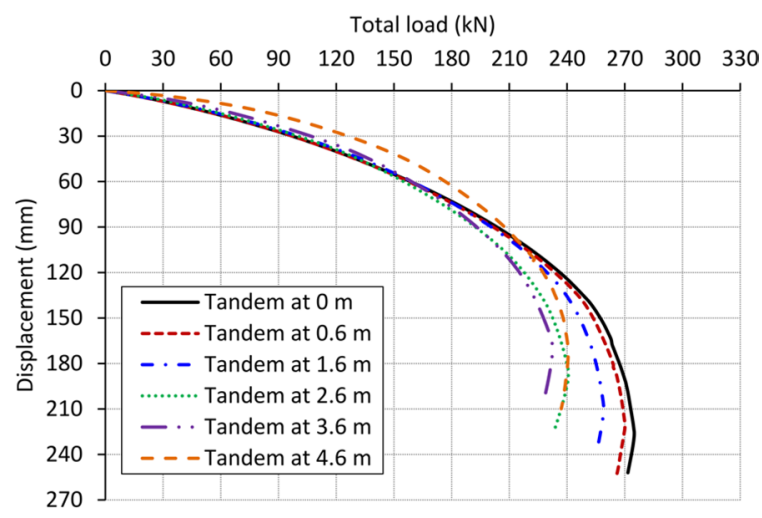

Fig. 7 Load-displacement curves for the different load positions as extracted form 2D models

displacement in both models. It is found that the same total displacement is taken place when the ratio between the total $2 \mathrm{D}$ load/3D tandem load is in the range of $0.24-0.26$. For instance, and for the case of having the tandem load at $4.6 \mathrm{~m}$, the total 2D load and the 3D tandem load at 48-mm displacement are about $161 \mathrm{kN}$ and $644 \mathrm{kN}$, respectively (a ratio of 0.25 ). Figure 8 also shows the live load vertical displacement of the arch where two selected models (2D and 3D) are compared at the same load ratio mentioned earlier. Figure 8 shows slightly lager vertical displacement values for the 2D case. On the other hand, if one uses Boussinesq's theory [62] and calculates the ratio between the total 2D load (two strips with 0.4-m width each) and the 3D tandem load which leads to the same vertical stress at $0.7 \mathrm{~m}$, that ratio would be about 0.485 . Additionally, design methods [5, 7] normally use an equivalent line load (calculated according to Boussinesq's theory) to represent the surface truck load, and for this case, the $2 \mathrm{D}$ equivalent line load will be about 0.25 times the $3 \mathrm{D}$ tandem load. In a way, the whole 3D tandem load is transferred to a single equivalent line load, where if used in the 2D model, it would lead to larger displacement values than the one presented here. In terms of the so-called live load spreading factor (LLDF) [9, 63, 64], for this case, if one uses Petersen et al. [63] method for the tandem loads with

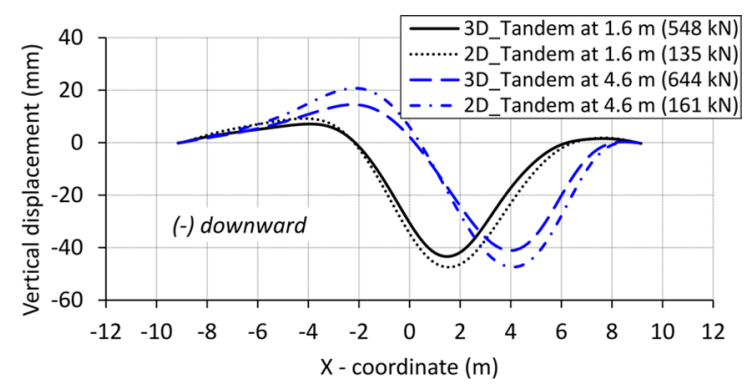

Fig. 8 Live load vertical displacement of the arch extracted at a load ratio of 0.25 between selected $2 \mathrm{D}$ and $3 \mathrm{D}$ models 


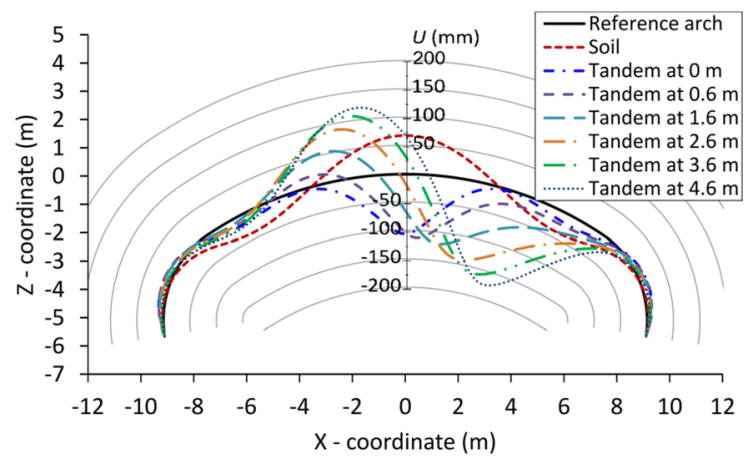

Fig. 9 Deformed shapes at failure for the different load cases of the 3D models (scaled up 20 times)

LLDF $=1.15$ (load distribution at one vertically to 0.575 horizontally), the calculated 2D equivalent line load will be about 0.21 times the 3D tandem load. More reflections regarding sectional forces differences between $2 \mathrm{D}$ and $3 \mathrm{D}$ models are also discussed in "Sectional forces".

The total deformed shapes at failure loads were also extracted for the different load cases as illustrated in Fig. 9. For instance, about 160-mm (180-mm load penetration at the surface) downward displacement at the crown area was needed to bring the structure to failure for the case of having the symmetrical tandem load and similar magnitudes of displacement were also observed for the other loading cases. In addition, one may also note that about $90-\mathrm{mm}$ (100-mm load penetration at the surface) crown downward displacement was needed to find the first yield area at $900-\mathrm{kN}$ tandem load for the case of symmetrical loading. These levels of displacement are regarded high considering the presence of road superstructures on the top, but at the same time provide important indications regarding the ductility of these structures. It is worth mentioning that the deformed shapes in Fig. 9 were extracted based on an arc section directly located under the wheel load. The distribution of the displacement in the transverse direction can be different for the different load cases. While a local distribution of the displacement under the loading pads is observed for the symmetrical loading case (Fig. 10), the displacement is seen more uniformly distributed in the transverse ( $Y$ direction) when the tandem load is located at $3.6 \mathrm{~m}$ from the crown (Fig. 11). It is worth noting that Figs. 10 and 11 do not share the same colour bar.

\section{Yield and Failure Loads}

Although Figs. 6 and 7 provide information regarding failure load for the different positions of the tandem load, it is also interesting to investigate and look at the evolution of yield loads for the different load cases. For all the loading cases, the failure has occurred after having several plastic hinges in the arch. Figure 12 presents the 1st yield, 2nd yield and

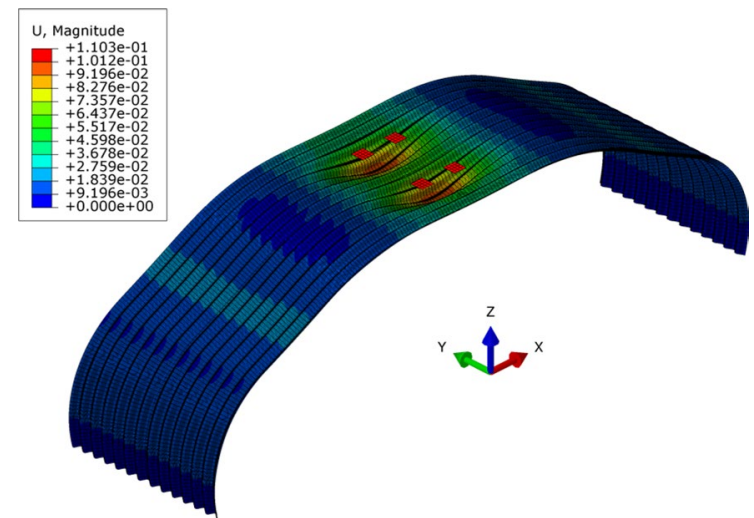

Fig. 10 Deformed shape at failure for the case having the tandem centred at crown (scaled up 10 times). Results are mirrored for better realisation

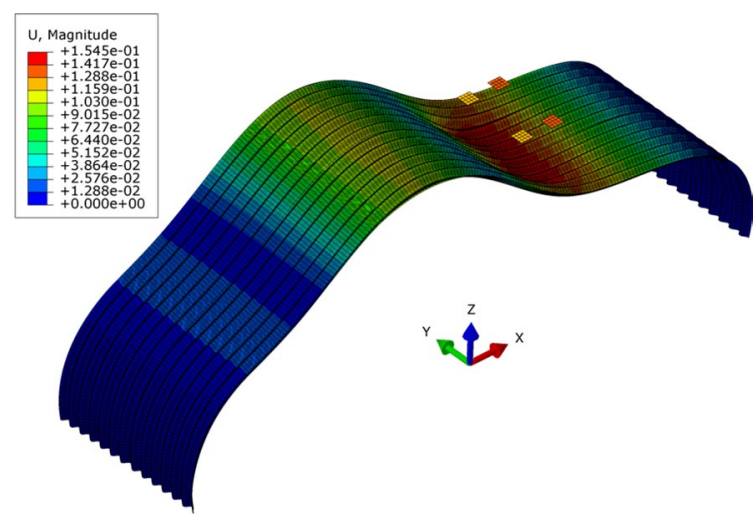

Fig. 11 Deformed shape at failure for the case of having the tandem at $3.6 \mathrm{~m}$ (scaled up 10 times). Results are mirrored for better realisation

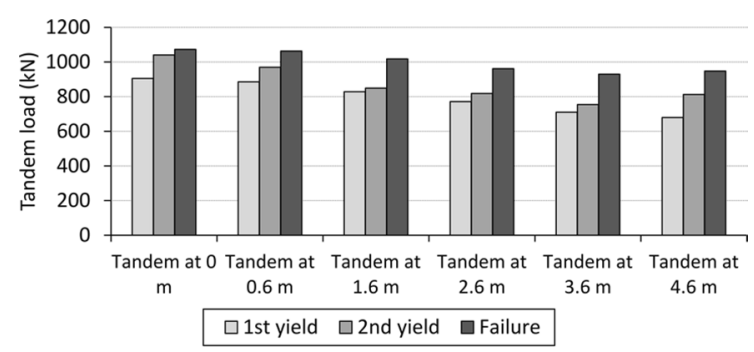

Fig. 12 Summary of 1st yield, 2nd yield and failure loads as extracted from 3D models

failure loads for the different load cases as extracted from the 3D model. The results show that the first yield load (i.e. the load at which the first appearance of yield area in the steel arch occurs) is decreasing when increasing the distance of the tandem load away from the crown. This is believed due to the initial stress state of the arch from the soil (i.e. backfilling) where this is further discussed later in "Sectional 
forces" and "Stresses in the arch". It is also interesting to highlight that the 1 st yield occurs at about $85 \%$ of the failure load for the symmetrical loading case and it occurs at $71 \%$ of the failure load when the tandem load is located at $4.6 \mathrm{~m}$ from the crown.

\section{Sectional Forces}

Normal forces and bending moments were calculated from the 3D models for the different load positions at loads just before yielding of the steel. These sectional forces presented in Figs. 13 and 14 were calculated based on the circumferential stresses (extreme top and bottom of the corrugation) of the steel arch just under the wheel pads. The calculated bending moments shown in Fig. 13 were seen considerably affected by the different load positions. Although that bending moments were depicted at different loads in Fig. 13, maximum values were captured when the tandem is centrically placed at crown. The same can be said for the calculated normal forces shown in Fig. 14. For instance, if one compares the maximum bending moments for the cases of the symmetrically placed tandem and when tandem is located at $4.6 \mathrm{~m}$, a $25 \%$ reduction of the tandem load (from $883 \mathrm{kN}$ to $659 \mathrm{kN}$ ) produces more than $50 \%$ reduction of the maximum positive moment. Similarly, normal forces are reduced way more when the two loading cases are compared as shown in Fig. 14. Despite this, the contribution of bending moments from the soil makes that the first yield of the steel is seen at a lower load when the tandem is located away from the crown. This significant influence of the soil load effects directly affects the evolution of yield in the steel arch and the subsequent formation of the failure mechanism. Figure 14 also shows a significant reduction of live load circumferential normal forces at foundation level particularly when the tandem is located around the crown area.

The circumference sectional forces shown in Figs. 13 and 14 were calculated based on a steel arc located directly under the loading pads, which represent the peak values. The

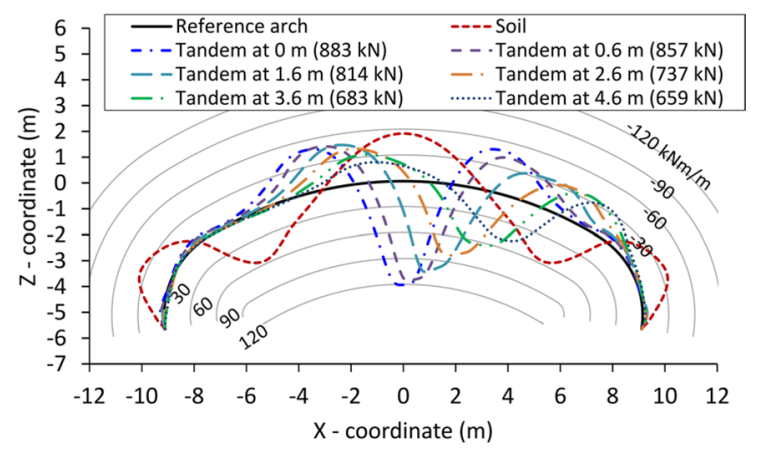

Fig. 13 Soil and live load bending moments extracted at tandem loads just before the first yield of the steel material as calculated from the 3D models

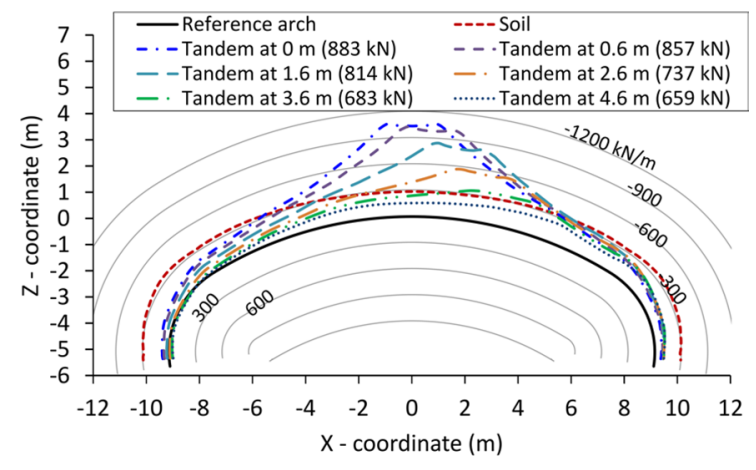

Fig. 14 Soil and live load normal forces extracted at tandem loads just before the first yield of the steel material as calculated from the 3D models

distribution of live load sectional forces across the width of the arch can also provide valuable insights on how forces are distributed in the transverse direction. For instance, Fig. 15 shows the distribution of sectional forces as calculated at 646-kN tandem load for two selected loading cases. While the local effect of the tandem load is clearly seen for the centrically loaded case, this effect is less observed for the asymmetrical loading case. This is also connected to the deformed shapes presented earlier in Figs. 10 and 11. Additionally, Fig. 16 shows the average normal force over a 1.14-m width of the corrugation (representing three pitches of $0.381 \mathrm{~m}$ ) calculated for the centrically loaded case. This can be compared with the same loading case in Fig. 14 where one may note that the maximum values of live load normal forces are reduced by $30 \%$ when they are calculated as an average of a 1.14-m width of the corrugation. This could be useful if one uses 3D simulations for designs, particularly in terms of bolted connections and applied forces on foundations.

On the other hand, Fig. 17 shows the live load sectional forces from both 3D and 2D models plotted for selected loading cases at a load ratio of 0.25 between the total 2D load and the 3D tandem load (see "Load-displacement

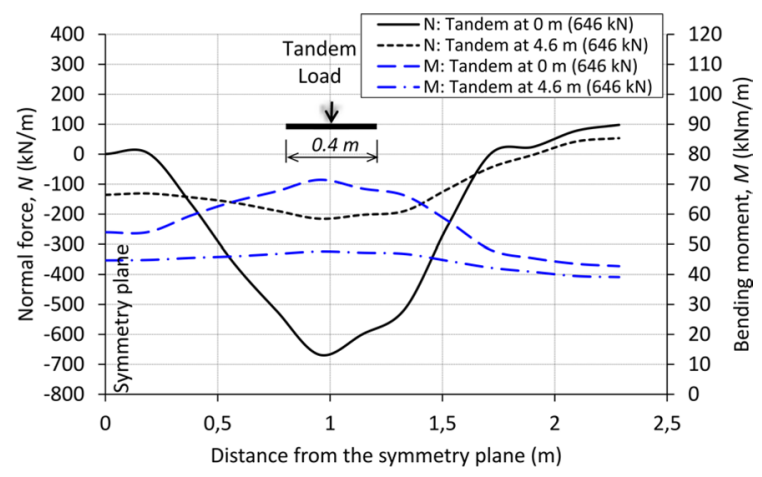

Fig. 15 Transverse distribution of sectional forces under loading pads shown for two loading cases extracted at about $646-\mathrm{kN}$ tandem load 


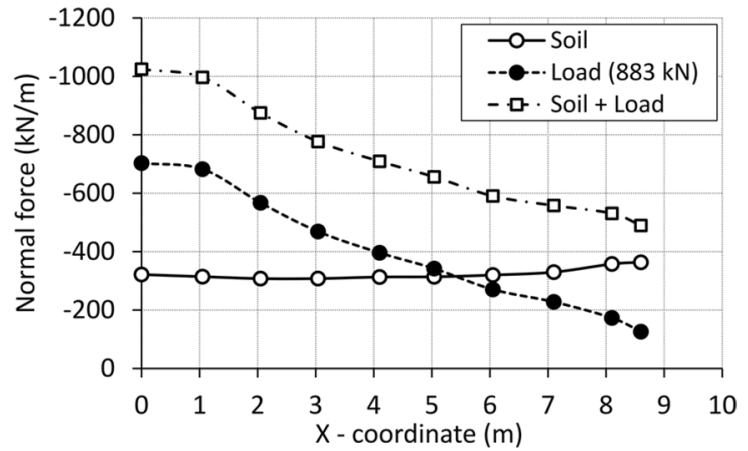

Fig. 16 Average normal forces calculated over a 1.14-m width of the corrugation for the case of centrically placed tandem

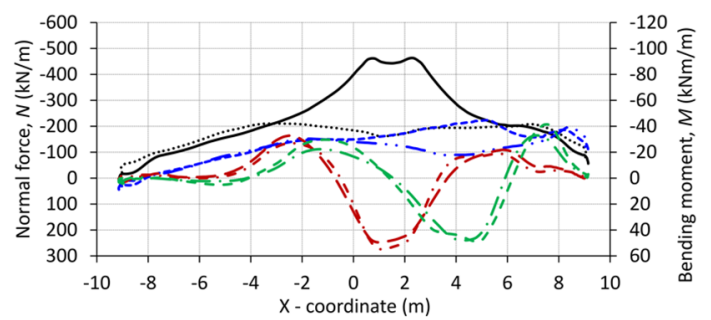

\begin{tabular}{|c|c|}
\hline -N_3D_Tandem at $1.6 \mathrm{~m}(548 \mathrm{kN})$ & $\cdots \cdots \cdot N$ N_2D_Tandem at $1.6 \mathrm{~m}(135 \mathrm{kN})$ \\
\hline -- N_3D_Tandem at $4.6 \mathrm{~m}(644 \mathrm{kN})$ & - $\cdot$ N_2D_Tandem at $4.6 \mathrm{~m}(161 \mathrm{kN})$ \\
\hline -M_3D_Tandem at $1.6 \mathrm{~m}(548 \mathrm{kN})$ & - -M_2D_Tandem at $1.6 \mathrm{~m}(135 \mathrm{kN})$ \\
\hline M 3D Tandem at $4.6 \mathrm{~m}(644 \mathrm{kN})$ & - - M 2D_Tandem at $4.6 \mathrm{~m}(161 \mathrm{kN})$ \\
\hline
\end{tabular}

Fig. 17 Live load sectional forces of the arch extracted at a load ratio of 0.25 between selected $2 \mathrm{D}$ and 3D models

curves"). It is clearly seen that although the load ratio of 0.25 represents a good correlation between $2 \mathrm{D}$ and $3 \mathrm{D}$ models in terms of live load displacements (Fig. 8) and bending moments (Fig. 17), this ratio is still far from being true when looking at the live load normal forces as illustrated is Fig. 17. At 0.25 load ratio, the live load normal forces from the $2 \mathrm{D}$ models were not matching the corresponding ones from the 3D models especially in the arch areas under the loads (Fig. 17). Indeed, there can be different results if one attempts to compare in other ways and taking into consideration the different approaches/assumptions in converting 3D loads into 2D. This clearly shows the complexity of having equivalent 2D models for the estimation of live load effects specially taking into consideration the proper idealisation of 3D loads into a 2D simulation environment. The same was concluded in previous studies $[11,52]$ where it was seen that two-dimensional analyses will clearly require the use of different 2D line loads (also in terms of LLDF) for calculations of deflection, moments, and axial force.

\section{Stresses in the Arch}

To visualise the yield areas for the different loading positions, one may look at the total circumferential stresses extracted at yield loads (Fig. 18). The 1st yield areas in the steel arch for the two selected cases were observed when the top corrugation reaches the yield stress of steel in compression. Both loading cases had their 1st yield areas under the centre of the tandem load. Obviously, the asymmetrical loading case yielded at a lower tandem load mainly because of the fact that the bending moments from both the soil and the live load had the same sign (positive) at the 1st area of yield (see also Fig. 13). Of course, the yield of steel is a result from both normal forces and bending moments with more pronounced effects of the latter especially for the asymmetrical loaded cases.

Figure 19 also shows the different locations of the yield areas in the steel arch as extracted at failure loads for the different loading cases. The 1st yield area of the steel arch is located directly under the tandem load expect for the 1.6-m and 2.6- $\mathrm{m}$ tandem location cases. These cases had their first yield area at a location where the live load negative bending moment occurs (see Fig. 13). At these locations, the live load negative bending moment is added to the soil negative bending moment (plus normal force) causing the 1st yield of steel by compression for the bottom of the corrugation. One may also observe form Fig. 19 that at failure load, yield areas are formed over the full section width of the arch for the extreme asymmetrical loading cases compared to their local nature for the less asymmetrical loading cases.

\section{Effect of Using Symmetry and Interface Modelling Choice}

So far, results were presented based on an assumed frictional interface between the backfill soil and the steel (see "3D model"). Apart from soil input parameters, a previous study [13] has showed that a tied interface (i.e. no-slip) was needed to reasonably reach a calibrated model of a studied case with the field measurements. Of course, the current study does not involve model calibration because it is conducted for a performance prediction of the studied case ahead of its field

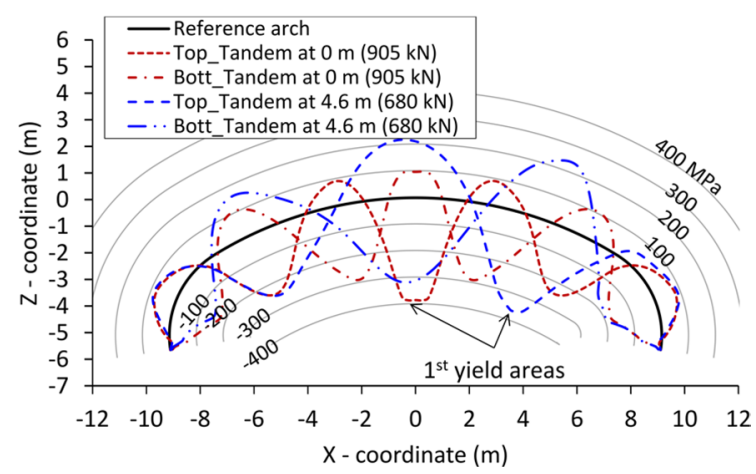

Fig. 18 Total circumferential stress along the arch for two selected loading cases as extracted at first yield loads of the steel (3D model) 

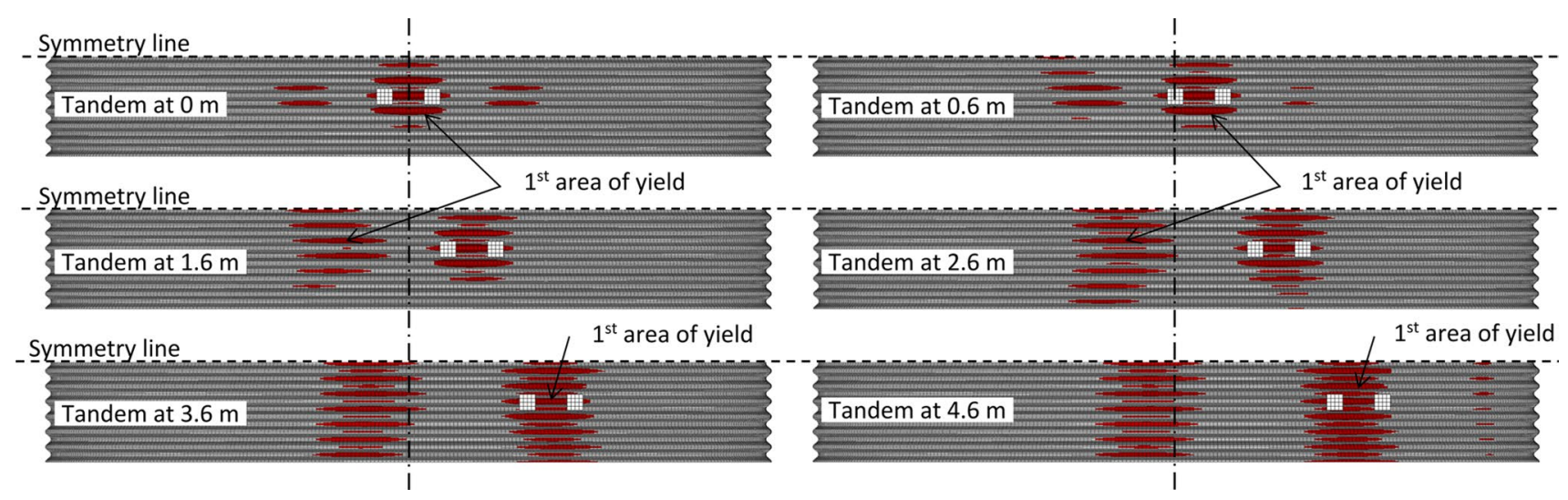

Fig. 19 Location of yield areas at failure for the different loading cases (based on von Mises stresses)

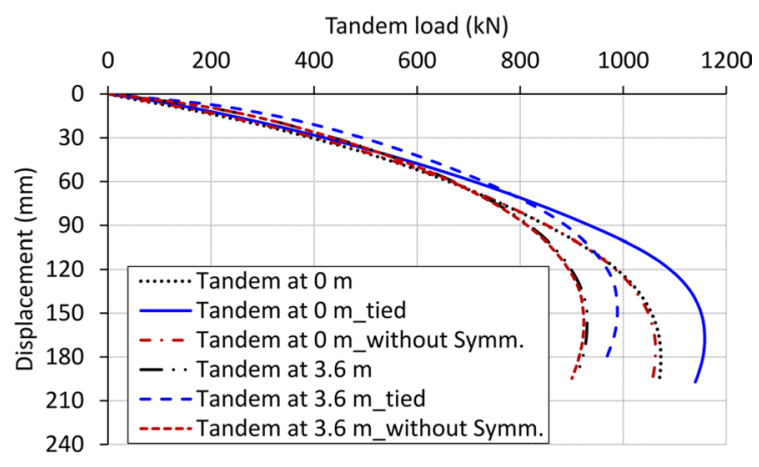

Fig. 20 Load-displacement curves comparison for different interface choices and the effect of using symmetry shown for two selected 3D models

testing. Yet, it is still interesting to get an idea on the effect of having a tied interface on the results.

Figure 20 shows a comparison of using a tied interface in terms of the load-displacement curves for two selected load positions. The results obviously show an increase of the failure load for both cases, and this increase is about $8 \%$ and $6 \%$ for the centrically loaded and the 3.6-m tandem distance cases, respectively. The calculated 1 st yield loads also increased by about $8 \%$ and $3 \%$ for the centrically loaded and the 3.6-m tandem distance cases, respectively (compare Fig. 12). A study was also made to see if using the symmetry in the built model of any influence on the results. Two load positions were chosen where full models are analysed without the use of symmetry. Figure 20 clearly shows that the use of symmetry has no influence on the structural response; also values of yield and failure loads remained unchanged. A comparison of live load bending moments also shows that at about $650-\mathrm{kN}$ tandem load, using a tied interface reduces the maximum bending moment by $11 \%$ and $23 \%$ for the centrically loaded and the 3.6-m tandem distance cases, respectively (Fig. 21).

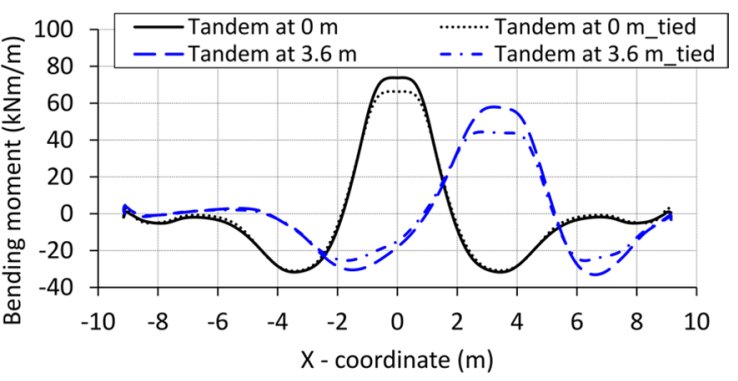

Fig. 21 Live load bending moments comparison for tied and frictional interface choices shown for two selected 3D models at about $650-\mathrm{kN}$ tandem load

\section{Conclusions}

In this study, FEM has been utilised to predict the ultimate capacity of a large-span SSCB pertaining to the ongoing preparations of a full-scale field test for the case. The effect of different load positions for a standard load model has been investigated. Although a 3D simulation is the natural way to go for the topic, 2D models were also included for comparison and limitations discussion. The effect of the backfilling process was also included as believed essential for a proper prediction of the ultimate capacity. The simulations were based only on a 700-mm soil cover, where this should be kept in mind when reading the following conclusions.

- The predicted response to soil loads (i.e. backfilling) was seen reasonable when linked to a comparable size tested structure.

- At a certain ratio between the 2D total load and the $3 \mathrm{D}$ tandem load, the structural response of the $2 \mathrm{D}$ and 3D models were similar in terms of live load bending moments and displacements. The same could not be said for the live load normal forces. 
- Naturally, 3D modelling is the proper way for the analysis of SSCB especially for the cases where live loads are governing the design. 2D models can lead to poor estimation of the live load effects, and thus should be used with care.

- For reasons believed to the soil loading effects, the loaddisplacements curves showed that it is more critical for the ultimate load when the tandem load is asymmetrically placed away from the crown.

- Live load bending moments and normal forces were maximised when the tandem load is centrically placed at the crown.

- For the first steel yield to occur, the calculated live load vertical displacements of the arch were about $90 \mathrm{~mm}$ and $40 \mathrm{~mm}$ for the symmetrical and the 4.6-m asymmetrical loading cases, respectively.

- The local distribution of live load effects was more pronounced when the tandem load is placed closer to the crown.

- The use of the tied interface caused a stiffer structural response compared to the models with the frictional interface.

- Although that the 3D simulations predicted a failure load of at least 1.5 times the characteristic standard tandem load (i.e. $2 \times 300 \mathrm{kN}$ ), these values are still based on the model assumptions specially the soil parameters, the interface, and the predicted structural response to soil load (i.e. backfilling). Nonetheless, the results themselves are believed to be conceptually true in terms of their prediction insights concerning the performance of a large-span SSCB. The instrumentation plan and the interrelated preparations for the planned full-scale field test will be mainly based on the findings of this article.

Acknowledgments The authors would like to acknowledge and express their gratitude to ViaCon Group and KTH Royal Institute of Technology for financially supporting this research. The simulations were mainly performed on resources provided by the Swedish National Infrastructure for Computing (SNIC) at PDC Centre for High Performance Computing (PDC-HPC).

Funding Open access funding provided by Royal Institute of Technology.

Open Access This article is licensed under a Creative Commons Attribution 4.0 International License, which permits use, sharing, adaptation, distribution and reproduction in any medium or format, as long as you give appropriate credit to the original author(s) and the source, provide a link to the Creative Commons licence, and indicate if changes were made. The images or other third party material in this article are included in the article's Creative Commons licence, unless indicated otherwise in a credit line to the material. If material is not included in the article's Creative Commons licence and your intended use is not permitted by statutory regulation or exceeds the permitted use, you will need to obtain permission directly from the copyright holder. To view a copy of this licence, visit http://creativecommons.org/licenses/by/4.0/.

\section{References}

1. White LH, Layer PJ (1960) The corrugated metal conduit as a compression ring. Highw Res Board Proc 39:389-397

2. Duncan JM (1978) Soil-culvert interaction method for design of metal culverts. Transp Res Rec (678):53-59

3. Duncan JM (1979) Behavior and design of long-span metal culverts. J Geotech Eng Div 105:399-418

4. Klöppel K, Glock D (1970) Theoretische und experimentelle untersuchungen zu den traglastproblemen biegeweicher, in die erde eingebetteter rohre. Institutes für Statik und Stahlbau der Technischen Hochschule Darmstadt, Darmstadt

5. Pettersson L, Bayoğlu Flener E, Sundquist H (2015) Design of soil-steel composite bridges. Struct Eng Int 25:159-172. https ://doi.org/10.2749/101686614X14043795570499

6. Pettersson L, Sundquist H (2014) Design of soil steel composite bridges, 5th edn. KTH Royal Institute of Technology, Stockholm

7. CSA Canadian Standards Association (2019) Canadian Highway Bridge Design Code S6-19, 12th edn. CSA Canadian Standards Association, Toronto

8. CSA Canadian Standards Association (2006) Commentary CAN/CSA-S6-06, Canadian Highway Bridge Design Code S6.1-06. CSA Canadian Standards Association, Toronto

9. AASHTO (2020) LRFD bridge design specifications. American Association of State Highway and Transportation Officials, Washington, DC

10. McGrath TJ, Moore ID, Selig ET, et al (2002) Recommended specifications for large-span culverts (NCHRP report 473). Transportation Research Board

11. Moore ID, Taleb B (1999) Metal culvert response to live loading: performance of three-dimensional analysis. Transp Res Rec 1656:37-44

12. Duncan JM, Chang CY (1970) Nonlinear analysis of stress and strain in soils. J Soil Mech Found Div 96:1629-1653

13. Wadi A, Pettersson L, Karoumi R (2018) FEM simulation of a full-scale loading-to-failure test of a corrugated steel culvert. Steel Compos Struct 27:217-227. https://doi.org/10.12989/ scs.2018.27.2.217

14. Mohammed H, Kennedy JB (1995) Simplified analysis of longspan soil-metal structures. J Struct Eng 121:1463-1470. https:// doi.org/10.1061/(ASCE)0733-9445(1995)121:10(1463)

15. Elshimi TM, Brachman RWI, Moore ID (2014) Effect of truck position and multiple truck loading on response of longspan metal culverts. Can Geotech J 51:196-207. https://doi. org/10.1139/cgj-2013-0176

16. Bayoğlu Flener E (2010) Soil-steel interaction of long-span box culverts-performance during backfilling. Geotech Geol Eng $136: 823-832$

17. Kunecki B (2014) Field test and three-dimensional numerical analysis of the soil-steel tunnel during backfilling. Transp Res Rec J Transp Res Board. https://doi.org/10.3141/2462-07

18. Bayoğlu Flener E, Karoumi R (2009) Dynamic testing of a soilsteel composite railway bridge. Eng Struct 31:2803-2811

19. Mellat P, Andersson A, Pettersson L, Karoumi R (2014) Dynamic behaviour of a short span soil-steel composite bridge for high-speed railways-field measurements and FE-analysis. Eng Struct 69:49-61

20. Beben D, Manko Z (2010) Dynamic testing of a soil-steel bridge. Struct Eng Mech 35:301-314

21. Beben D (2013) Experimental study on the dynamic impacts of service train loads on a corrugated steel plate culvert. J Bridge Eng 18:339-346. https://doi.org/10.1061/(ASCE)BE.19435592.0000395 
22. Beben D (2013) Dynamic amplification factors of corrugated steel plate culverts. Eng Struct 46:193-204. https://doi. org/10.1016/j.engstruct.2012.07.034

23. Leander J, Wadi A, Pettersson L (2017) Fatigue testing of a bolted connection for buried flexible steel culverts. In: III European Conference on Buried Flexible Steel Structures, Rydzyna, Poland. Wydawnictwo Politechniki Poznanskiej, Rydzna, Poland 23:153-162

24. Webb MC, Selig E, Sussmann J, Mcgrath T (1999) Field tests of a large-span metal culvert. Transp Res Rec J Transp Res Board 1656:14-24. https://doi.org/10.3141/1656-03

25. Vaslestad J, Madaj A, Janusz L (2002) Field measurements of long-span corrugated steel culvert replacing corroded concrete bridge. Transp Res Rec 1814:164-170

26. Bayoğlu Flener E (2010) Testing the response of box-type soilsteel structures under static service loads. J Bridge Eng 15:90-97. https://doi.org/10.1061/(ASCE)BE.1943-5592.0000041

27. Timothy S, Halil S, Moore ID (2015) Joint response of existing pipe culverts under surface live loads. J Perform Constr Facil 29:4014037. https://doi.org/10.1061/(ASCE)CF.1943-5509.00004 94

28. Liu Y, Moore ID, Hoult NA (2020) Field monitoring of a corrugated steel culvert using multiple sensing technologies. J Pipeline Syst Eng Pract 11:04020030. https://doi.org/10.1061/(ASCE) PS.1949-1204.0000477

29. Liu Y, Hoult NA, Moore ID (2020) Structural performance of inservice corrugated steel culvert under vehicle loading. J Bridge Eng 25:04019142. https://doi.org/10.1061/(ASCE)BE.19435592.0001524

30. Beben D (2013) Field performance of corrugated steel plate road culvert under normal live-load conditions. J Perform Constr Facil 27:807-817. https://doi.org/10.1061/(ASCE)CF.1943-5509.00003 89

31. Morrison T (2000) Long-span deep-corrugated structural plate arches with encased-concrete composite ribs. Transp Res Rec J Transp Res Board 1736:81-93. https://doi.org/10.3141/1736-11

32. Alireza S, Mohammad R, Sadegh MM (2017) Field test of a largespan soil-steel bridge stiffened by concrete rings during backfilling. J Bridge Eng 22:6017002. https://doi.org/10.1061/(ASCE) BE.1943-5592.0001102

33. Becerril García D, Moore ID (2015) Performance of deteriorated corrugated steel culverts rehabilitated with sprayed-on cementitious liners subjected to surface loads. Tunn Undergr Space Technol 47:222-232. https://doi.org/10.1016/J.TUST.2014.12.012

34. Bayoğlu Flener E (2009) Response of long-span box type soilsteel composite structures during ultimate loading tests. J Bridge Eng 14:496-506. https://doi.org/10.1061/(ASCE)BE.19435592.0000031

35. Pettersson L (2007) Full scale tests and structural evaluation of soil steel flexible culverts with low height of cover [Ph.D. thesis, Bulletin 93]. KTH Royal Institute of Technology

36. Temporal J, Barratt A D, Hunnibell BEF (1985) Loading tests on an ARMCO pipe arch culvert. Research report. TRRL Res Rep

37. Brachman RWI, Moore ID, Mak AC (2010) Ultimate limit state of deep-corrugated large-span Box culvert. Transp Res Rec. https ://doi.org/10.3141/2201-07

38. Regier C, Hoult NA, Moore ID (2017) Laboratory study on the behavior of a horizontal-ellipse culvert during service and ultimate load testing. J Bridge Eng 22:4016131. https://doi. org/10.1061/(ASCE)BE.1943-5592.0001016

39. Yeau KY, Halil S (2014) Simulation of behavior of in-service metal culverts. J Pipeline Syst Eng Pract 5:04013016

40. Choi D-H, Kim G-N, Byrne PM (2004) Evaluation of moment equation in the 2000 Canadian highway bridge design code for soil-metal arch structures. Can J Civ Eng 31:281-291. https:// doi.org/10.1139/103-097
41. Seed RB, Raines JR (1988) Failure of flexible long-span culverts under exceptional live load. Transp Res Rec (1191):22-29

42. Girges Y, Abdel-Sayed G (1995) Three-dimensional analysis of soil-steel bridges. Can J Civ Eng 22:1155-1163. https://doi. org/10.1139/195-133

43. El-Sawy KM (2003) Three-dimensional modeling of soil-steel culverts under the effect of truckloads. Thin Walled Struct 41:747-768

44. Abdel-Sayed G, Salib SR (2002) Minimum depth of soil cover above soil-steel bridges. J Geotech Geoenviron Eng 128:672-681

45. El-Taher M, Moore ID (2008) Finite element study of stability of corroded metal culverts. Transp Res Rec J Transp Res Board. https ://doi.org/10.3141/2050-16

46. Elshimi TM (2011) Three-dimensional nonlinear analysis of deepcorrugated steel culverts [Ph.D. thesis]. Ontario, Canada: Queen's University

47. Taleb B, Moore ID (1999) Metal culvert response to earth loading: performance of two-dimensional analysis. Transp Res Rec 1656:25-36

48. Alzabeebee S, Chapman DN, Faramarzi A (2018) A comparative study of the response of buried pipes under static and moving loads. Transp Geotech 15:39-46. https://doi.org/10.1016/j.trgeo .2018.03.001

49. Wadi A, Pettersson L, Karoumi R (2015) Flexible culverts in sloping terrain: numerical simulation of soil loading effects. Eng Struct 101:111-124. https://doi.org/10.1016/j.engst ruct.2015.07.004

50. Wadi A, Pettersson L, Karoumi R (2016) Flexible culverts in sloping terrain: numerical simulation of avalanche load effects. Cold Reg Sci Technol 124:95-109. https://doi.org/10.1016/j.coldregion s.2016.01.003

51. Beben D, Stryczek A (2016) Numerical analysis of corrugated steel plate bridge with reinforced concrete relieving slab. J Civ Eng Manag 22:585-596. https://doi.org/10.3846/13923 730.2014 .914092

52. Moore ID, Brachman RW (1994) Three dimensional analysis of flexible circular culverts. J Geotech Eng 120:1829-1844. https:// doi.org/10.1061/(ASCE)0733-9410(1994)120:10(1829)

53. Beben D, Wrzeciono M (2017) Numerical analysis of steel-soil composite (SSC) culvert under static loads. Steel Compos Struct 23:715-726. https://doi.org/10.12989/scs.2017.23.6.715

54. Lougheed A (2008) Limit states testing of a buried deep-corrugated large-span box culvert [MSc thesis]. Ontario, Canada: Queen's University

55. Machelski C, Tomala P, Kunecki B, et al (2017) UltraCor-1st realization in europe, design, errection and testing. In: III European Conference on Buried Flexible Steel Structures, Rydzyna, Poland. Wydawnictwo Politechniki Poznanskiej, Rydzna, Poland 23:189-197

56. ViaCon Poland (2020) https://viacon.pl. Accessed 10 Mar 2020

57. European Committee for Standardization (2003) Eurocode 1actions on structures - part 2: traffic loads on bridges, EN 1991-2. CEN, Brussels

58. Dassault Systemes SIMULIA Corp. (2017) Abaqus 2017

59. Plaxis bv (2016) Plaxis 2D material models manual

60. Bowles JE (1997) Foundation analysis and design, 5th edn. McGraw-Hill Companies, New York

61. Korusiewicz L, Kunecki B (2012) Field test of a large-span soil-steel arch without stiffeners during backfilling operations. In: II European Conference on Buried Flexible Steel Structures, Rydzyna, Poland. Wydawnictwo Politechniki Poznanskiej, Rydzna, Poland 12:133-139

62. Das BM (2006) Principles of geotechnical engineering, 6th edn. Thomson Learning, Boston

63. Petersen DL, Nelson CR, Li G, et al (2010) Recommended design specifications for live load distribution to buried structures 
64. Mai VT, Moore ID, Hoult NA (2014) Performance of twodimensional analysis: deteriorated metal culverts under surface live load. Tunn Undergr Space Technol 42:152-160. https://doi. org/10.1016/j.tust.2014.02.015
Publisher's Note Springer Nature remains neutral with regard to jurisdictional claims in published maps and institutional affiliations. 